\title{
ICT MEMUNGKINKAN ORANG BEKERJA DARI RUMAH: STUDI KASUS PADA BANK DAN KURSUS ONLINE
}

\author{
Yuliana Lisanti \\ Information Systems Department, School of Information Systems, Binus University \\ Jl. K.H. Syahdan No. 9, Palmerah, Jakarta Barat 11480 \\ lisanti@binus.edu
}

\begin{abstract}
The Information technology and telecommunications (ICT - Information and Communication Technology) utilization to facilitate the home worker or teleworker has started being implemented in many companies. The study showed that the home worker offers benefits such as offering the flexibility to improve employee's work-life balance, cost savings from hot desking implementation, which also support the clean desk policy implementation. In addition, the government needs to encourage firms to adopt the work from home concept, as it can helps to facilitate housewives hence they can have additional income, furthermore, the home worker could help to solve social problems such as traffic congestion in major cities.
\end{abstract}

Keywords: information technology, telecommunication, ICT, home worker, teleworker, work-life balance, cost saving

\begin{abstract}
ABSTRAK
Penggunaan teknologi informasi dan telekomunikasi (ICT - Information and Communication Technology) untuk memfasilitasi home worker atau teleworker sudah mulai banyak di implementasikan di perusahaan. Hasil penelitian menunjukkan bahwa banyak keuntungan yang didapat dari implementasi bekerja dari rumah ini, di antaranya adalah menawarkan fleksibilitas sehingga meningkatkan keseimbangan kehidupan dengan pekerjaan seorang pegawai, penghematan biaya dari penerapan hot desking, yang juga mendukung kegiatan clean desk policy. Pemerintah perlu untuk mendorong perusahaan untuk menerapkan bekerja dari rumah ini karena dapat mendorong pendapatan income memfasilitasi ibu rumah tangga untuk bekerja juga membantu menyelesaikan masalah sosial di kota besar, seperti kemacetan.
\end{abstract}

Kata kunci: teknologi informasi, telekomunikasi, ICT, bekerja dari rumah, keseimbangan kehidupan dengan pekerjaan, penghematan biaya 


\section{PENDAHULUAN}

Bekerja dan menjadi wanita karir, atau menjadi ibu rumah tangga untuk mengurus keluarga merupakan salah satu dilema yang biasanya dihadapi oleh seorang ibu rumah tangga. Dr Phil (2009) yang mendiskusikan topik "Stay-at-Home Moms vs. Working Moms” dengan Joan K Peters, pengarang buku "when mother work" menyarankan para ibu untuk mengambil keputusan yang paling mendekati dapat memenuhi harapan dan ekpektasi mereka. Namun tidak mudah untuk mengambil keputusan tersebut karena keduanya sama pentingnya. Elly Risman (2013), seorang pakar parenting di indonesia mengatakan bahwa tidak ada yang salah seorang wanita menempuh karir, dengan perkembangan teknologi pada saat ini, sangat memungkinkan seseorang mengembangkan kariernya sebagai sambilan dari menjadi ibu.

Di Singapura, survei yang dilakukan oleh depertemen tenaga kerja Singapura pada tahun 2010 menunjukan bahwa ada 270 ribu penduduk tidak aktif (bekerja) di usia produktif antara 25 - 54 tahun, di mana $85 \%$ nya adalah wanita. Mengurus keluarga adalah alasan utama yang dikemukakan pada saat survei dilakukan, dan mereka masih mempunya keinginan untuk bekerja dan mempunyai karir. Untuk menjawab tantangan di atas, di mana para ibu produktif dihadapkan pada dua pilihan yang sama pentingnya, pada tahun 2013, Jalote (2003) dalam artikelnya di futuregov.asia menuliskan bawah pemerintah Singapura, melalui IDA (Infocomm Development Authority of Singapore) membuat sebuah pilot project mengenai home-based work. Pemerintah singapura mendukung dan menyarankan perusahaan-perusahaan di Singapura untuk menerapkan ICT (information computer dan telecommunication) dalam mengimplementasikan jam kerja yang fleksibel bagi karyawannya.

Sementara di negara-negara maju lainnya, seperti Amerika maupun Negara-negara di Eropa, penerapan ICT yang memungkinkan karyawan bekerja dari rumah sudah di implementasikan oleh banyak perusahaan. Inisiatif bekerja dari rumah merupakan salah satu cara untuk mencapai keseimbangan antara kehidupan pribadi dan pekerjaan (work-life balance), di mana pekerja memiliki waktu dan kualitas yang sama untuk bekerja dan juga untuk hidup seperti waktu untuk keluarga dan kegiatan sosial lainnya. work-life balance dipercaya dapat meningkatkan kepuasan karyawan yang ditempatkan pada perspective learning and growth di Balanced Scorecard (BSC). Peningkatan kepuasan karyawan dipercaya dapat meningkatkan proses, kualitas dan produktifitas dari produk dan jasa perusahaan (perspective Internal business process), sehingga dapat meningkatkan kepuasan pelanggan (perspective customer), yang pada akhirnya dapat mendukung peningkatan profit perusahaan di perspectice financial (Kaplan, 2010).

Namun demikian, Crosbie dan Moore (2004) di dalam tulisannya yang berjudul work-life balance and working from home mengemukakan bahwa bekerja dari rumah merupakan salah satu perwujudan dari inisiatif jam kerja fleksibel yang memberikan banyak pilihan kepada pegawai, tetapi harus ada proses, pedoman, dan kebijakan yang mengatur kegiatan ini, sehingga bekerja dari rumah bisa memberikan manfaat yang lebih bagi karyawan juga perusahaan.

Berdasarkan studi terhadap perusahaan yang sudah menjalankan home working atau teleworking, tulisan ini akan difokuskan untuk menjelaskan bagaimana implementasi home working dengan bantuan Teknologi Informasi dan Telekomunikasi dan memberikan penjelasan manfaat dan benefit dari home working.

Hal-hal yang dibahas pada tulisan ini antara lain: (1) Bagaimana teknologi informasi dan telekomunikasi (ICT) memungkinkan seorang pekerja untuk melakukan pekerjaannya dari rumah? (2) Bagaimana pelaksanaan dan implementasinya? (3) Apa saja benefit dan tantangannya? (4) Bagaimana perkembangan home worker di Indonesia, khususnya Jakarta? 
Artikel ini bertujuan untuk: (1) menjelaskan bagaimana Teknologi informasi dan telekomunikasi (ICT) dapat memungkinkan seorang pekerja untuk melakukan pekerjaannya dari rumah; (2) menjelaskan solusi Teknologi Informasi dan telekomunikasi yang digunakan didalam mendukung home worker ; (3) menjelaskan apa saja manfaat dan tantangan dari home worker ; (4) menjelaskan potensi perkembangan home worker di Indonesia, khususnya Jakarta.

\section{METODE}

Untuk mencapai tujuan penelitian ini, yaitu untuk mengetahui bagaimana pelaksanaan dan implementasi bekerja dari rumah, penelitian dan pelaporan dilakukan dengan pendekatan metode deskriptif kualitatif. Deskriptif kualitatif berarti bersifat menjelaskan atau menggambarkan sesuau dalam arti sebenarnya dan sesuai dengan kejadian. Data didapat dengan cara melakukan interview, wawancara, dan melakukan field research atau study case, dalam hal ini penulis melakukan research di bank (PT “XYZ”) dan online training bahasa inggris (PT “ABC”). Selain itu, studi pustaka juga dilakukan sebagai rujukan referensi tulisan ini. Interview dilakukan kepada 12 orang pegawai di PT "XYZ" yang menggunakan solusi Teknologi Informasi sebagai home worker, juga sudah mengimplementasi hot desking, selain itu wawancara juga dilakukan kepada 9 orang pegawai PT “ABC” yang berprofesi sebagai tenaga online English lecture.

\section{HASIL DAN PEMBAHASAN}

\section{Bagaimana (ICT) Memungkinkan Seorang Bekerja dari Rumah?}

Alexander, et al. (2010), dalam penelitiannya yang berjudul Working from 9 to 6? An analysis of in-home and out-of-home working schedules, mengemukakan bahwa karakteristik pegawai dan ICT merupakan faktor yang penting bagi perusahaan untuk memberikan jam kerja fleksibel seperti bekerja dari rumah kepada pegawainya di banding faktor lainnya seperti sociodemography. Secara empiris mereka juga menemukan korelasi yang kuat antara ICT dan pegawai yang memiliki fleksibel working hour. Research di atas, menunjukan bahwa ICT berperan penting didalam implementasi dari bekerja dari rumah, lalu bagaimana ICT bisa menjadi faktor penentu didalam implementasi bekerja dari rumah? studi kasus terhadap PT “XYZ” dan PT “ABC” akan menjelaskan dan menggambarkan bagaimana pegawai di kedua perusahaan itu bekerja dengan menggunakan ICT.

PT "XYZ” adalah sebuah international bank yang memiliki ribuan pegawai di lebih dari 20 negara. Sebagai salah satu inisiatif untuk meningkatkan kepuasan karyawan, PT "XYZ" berkomitmen untuk meningkatkan work-life balance pegawainya, sehingga mereka bisa membagi waktu mereka untuk bekerja dan keluarga, termasuk kegiatan sosialnya. Inisiatif ini diawali dari bagian IT support. Sebagai salah satu bagian yang memiliki turn over yang cukup tinggi karena nature dari pekerjaannya yang menuntuk komitmen yang tinggi dalam menjaga sistem perbankan untuk tetap available selama 24 X 7 (i.e internet banking, ATM, call center, dan sebagainya), juga tingginya permintaan di pasar untuk jenis pekerjaan ini. Selain itu, dinilai dari sisi kebutuhan, di mana seorang IT support harus dapat melakukan pekerjaanya kapan saja (termasuk di akhir minggu atau liburan), konsep home working ini di pilih untuk di terapkan dibagian ini.

Dengan sebuah multimedia laptop, koneksi internet berkecepatan tinggi atau mobile internet (3G) yang kebanyakan sudah dimiliki oleh semua pegawainya, dilengkapi dengan RAS (remote access service) untuk mengakses VPN (Virtual Private Network) kantor, selama 2 hari dalam seminggu pegawai dapat bekerja dari rumah. 
Gambar 1 menunjukan IPSec dan VPN design, yaitu standard dari virtual private network yang menggunakan network cryptographic protocols untuk mengenkripsi traffic sehingga dapat memberikan secure tunnel kepada pengguna home working atau teleworker juga mobile user, untuk dapat mengakses jaringan di kantornya melalui public network seperti Internet. Ini merupakan teknologi yang digunakan untuk memungkinkan akses bagi pekerja home working.

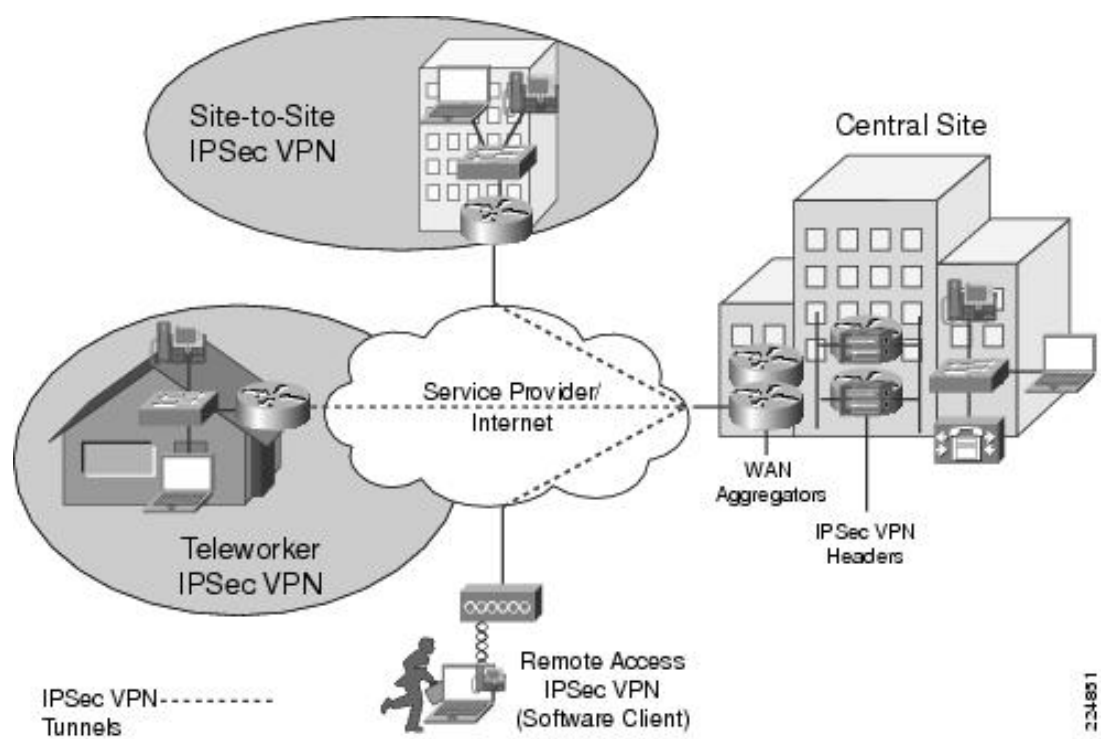

Gambar 1 IPSec VPN Design Contexts (CISCO, 2012)

Tugas-tugas IT support didistribusikan oleh service manager-nya melalui email atau aplikasi IT incident Management (Gambar 2) yang dapat memberikan peringatan otomatis ke perangkat mobile seorang support. Dengan aplikasi ini tugas-tugas atau tiket dapat di-track oleh user yang membutuhkan bantuannya maupun managernya.

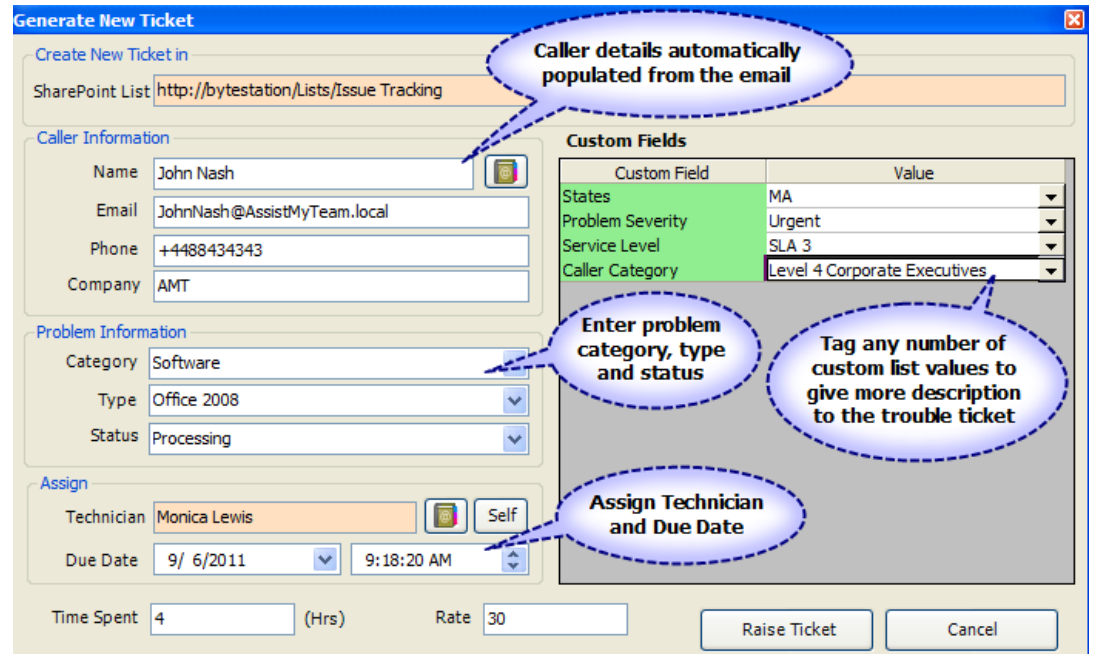

Gambar 2 IT Incident Tiket (issuetracketSP-Microsoft) 
IT support harus mampu untuk menyelesaikan masalah tersebut sesuai dengan SLA (service level agreement). Jika membutuhkan bantuan untuk menyelesaikan masalahnya ini, IT support akan meng-eskalasi ke second level support (support level ke dua) dan seterusnya.

Sementara untuk berdiskusi dengan user maupun koleganya melauli telepon maupun melakukan video conference, home worker user akan menggunakan aplikasi VOIP, seperti Cisco IP Communicator (Gambar 3) . Aplikasi voice over IP ini memungkinkan user menghubungi IT support di mana saja (setelah dia mengakses jaringan kantor) dengan menggunakan nomer telepon atau extension yang sama dengan yang digunakan di kantor.

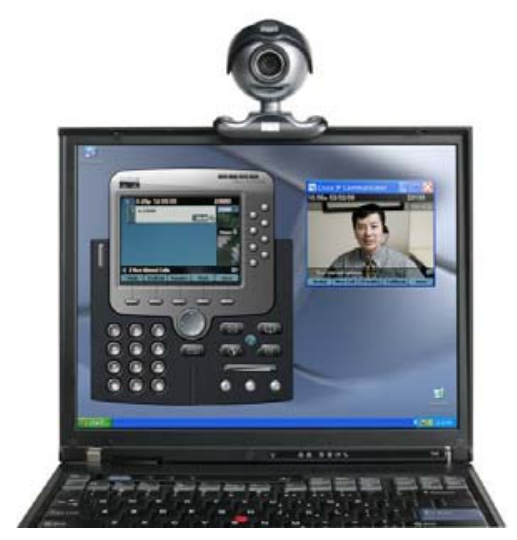

Gambar 3 Aplikasi VOIP (CISCO, 2007)

Selain itu, home worker juga dapat mengecek dan membalas email-email atau pesan (melalui jalur chat) yang masuk melalui laptopnya (Gambar 4) atau Blackberry yang diberikan oleh kantornya. Pada akhir hari, seorang IT support akan membuat summary incident report yang harus dikirimkan ke service manager-nya.

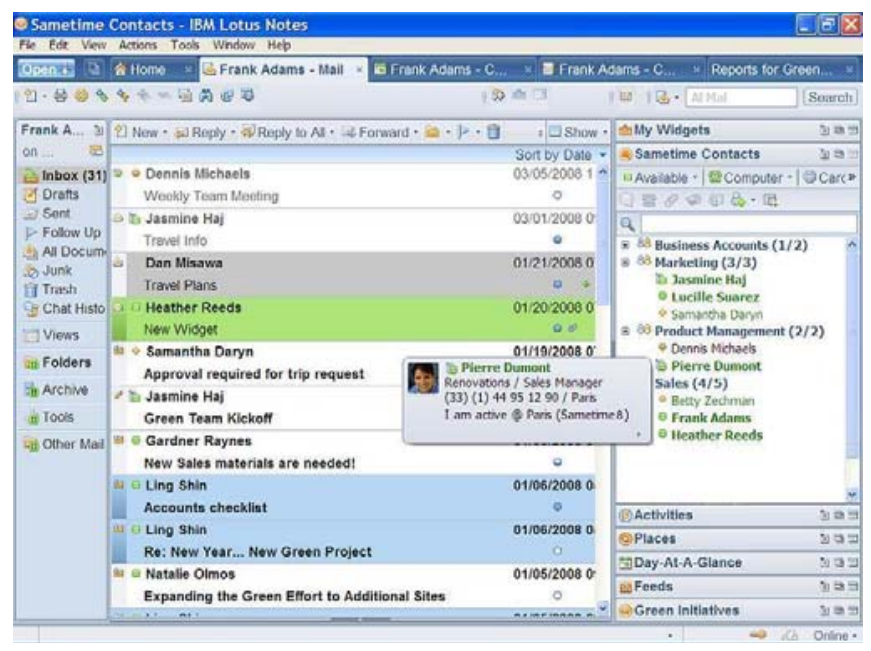

Gambar 4 Email dan messaging service (Lotus notes dan Sametime)

Implementasi home worker di bagian IT support pada tahun 2010-an, telah diterapkan juga di bagian lain, misalnya di bagian project. 
Seorang project manager akan menggunakan aplikasi project management untuk memanage project, mendistribusikan task, menangani issue di project, memonitor progress dari project dan membuat laporan project progress kepada managernya (Gambar 5).

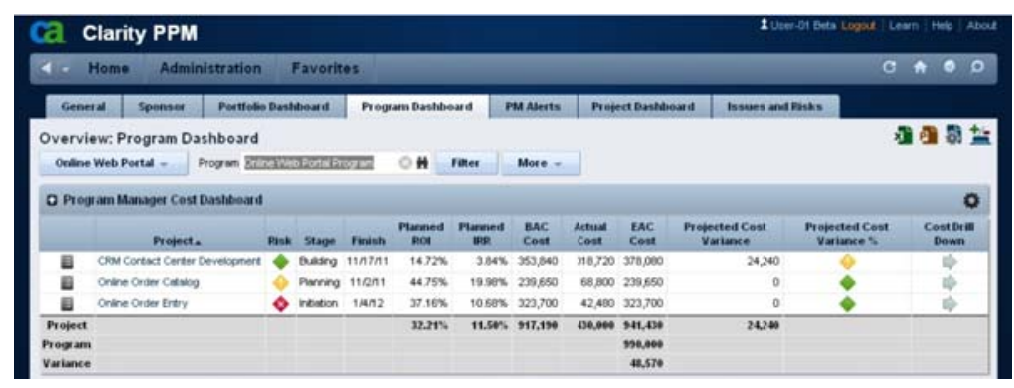

Gambar 5 Project Management Software (CA)

Sementara untuk berdiskusi untuk membahas project progress dengan tim membernya, seorang project manager akan menggunakan bantuan aplikasi online conference seperti WEBEX (Gambar 6). Dengan aplikasi ini, ia dapat membagi-pakai dokumennya sehingga setiap peserta dapat melihat materi yang sedang dipresentasikan.

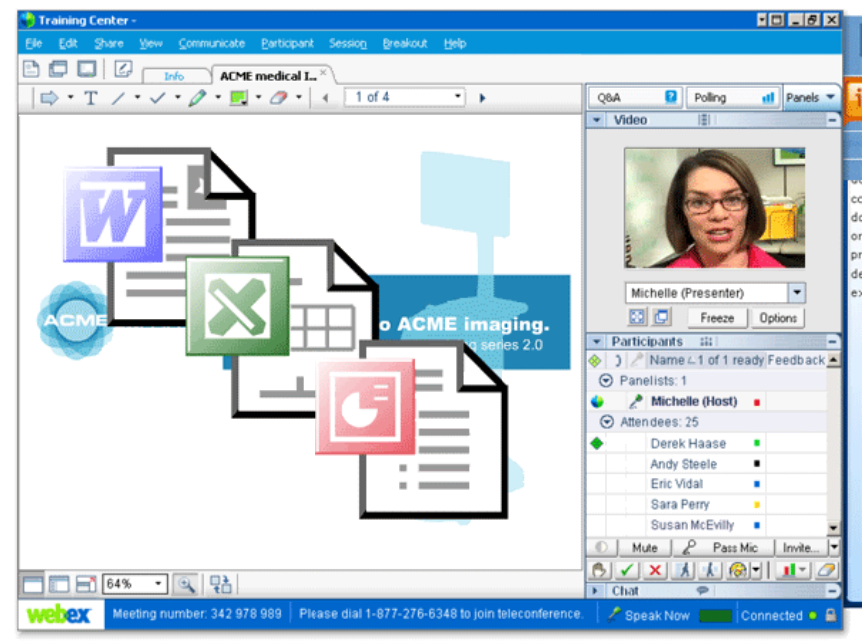

Gambar 6 Online Conference tool (Photo Bucket)

Penerapan home working policy di PT “XYZ” yang membolehkan pegawainya utnuk bekerja di rumah selama dua hari dalam seminggu, telah mendukung penerapan inisatif lainnya untuk mendukung penghematan biaya yaitu "hot desking” policy (Gambar 7). Hot desking adalah penggunaan suatu lokasi kerja oleh beberapa pegawai dalam waktu yang berbeda. Jadi seorang pegawai tidak memiliki meja tetap di kantor. Ia bisa duduk di setiap lokasi kerja yang ada. Hot desking di percaya dapat menghemat sampai 30\% dari biaya sewa dan biaya pendukung lainnya.

Selain itu dengan implementasi hot desking, seorang pegawai akan menyimpan dokumen atau barang barang pribadi karyawan di sebuah loker, yang sudah disiapkan oleh perusahaan. Inisiatif ini juga mendukung kebijakan Clean desk policy yang sangat penting bagi sebuah bank. Clean desk policy adalah sebuah kebijakan di mana seorang pegawai harus merapihkan mejanya sehingga tidak boleh ada dokumen-dokumen rahasia yang ditinggalkan pada akhir hari, termasuk informasi rahasia lainnya, 
seperti business card, post it, atau kunci loker yang biasanya diletakan di meja kerja (Priveate Sense, 2011). Hal ini untuk menjaga kerahasiaan data (misalnya data rekening pelanggan perbankan) dari kebocoran yang bisa diakibatkan dari aktifitas pencurian data melalui meja kerja seorang pegawai.

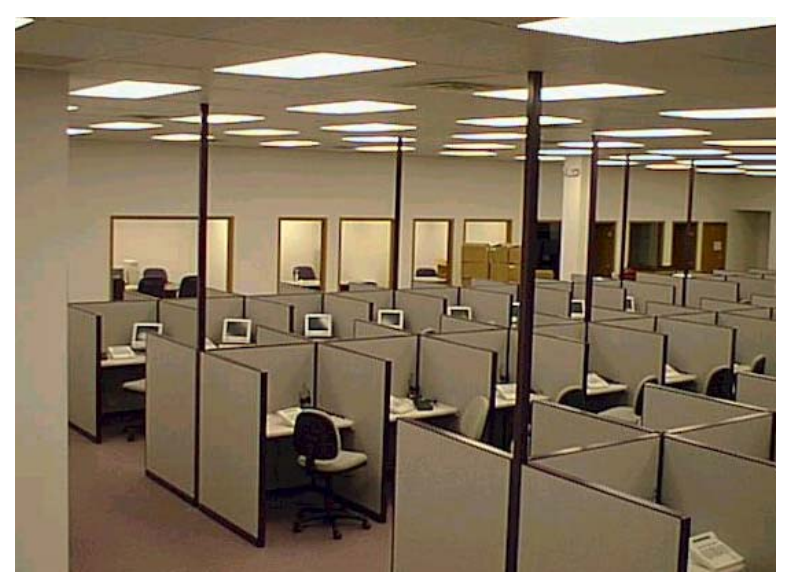

Gambar 7 Hot desking (Kleinsoffice)

Sementara itu, studi di sebuah kursus bahasa Inggris online PT “ABC” yang kegiatan belajar mengajar dilakukan sepenuhnya dengan metode home-based worker, menunjukan bahwa dengan perkembangan teknologi informasi dan telekomunikasi pada saat ini, konsep home working sudah dapat di implementasikan dengan terpercaya. Dengan bantuan sebuah laptop multimedia, akses internet berkecepatan tinggi, seorang pengajar di PT “ABC” akan menggunakan aplikasi online interaktif Conversation Class (Gambar 8) yang dibangun oleh $\mathrm{PT}$ “ABC” untuk mengajar secara live program pelatihan kelas percakapan bahasa Inggris.

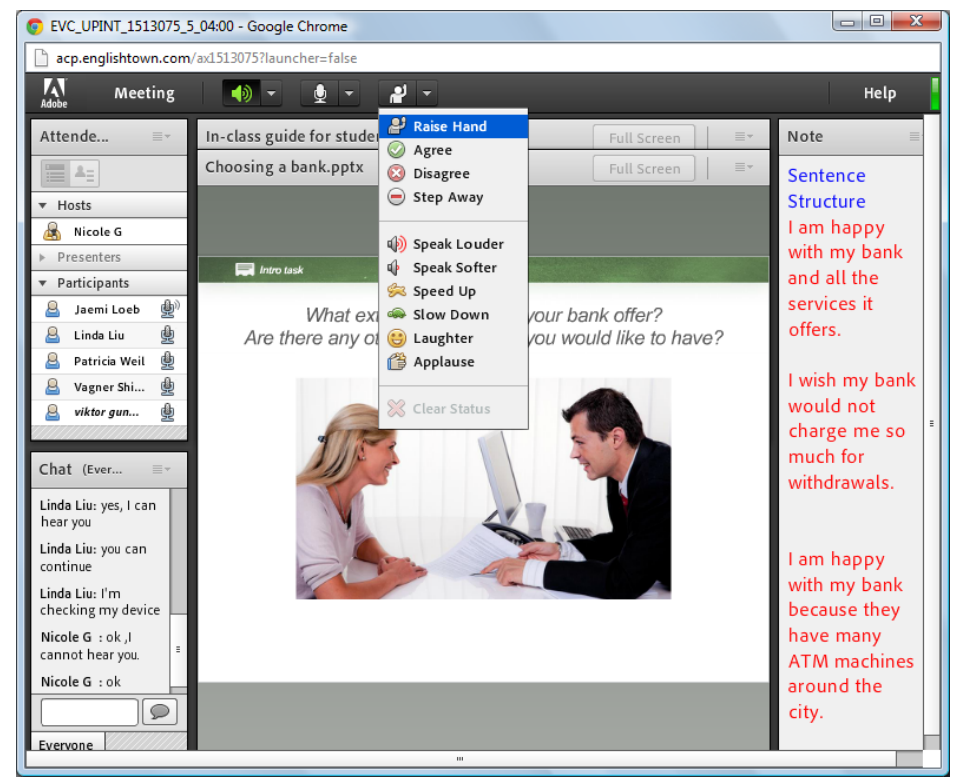

Gambar 8 Interactive online class (EF English First) 
Conversation class, merupakan interactive online class sehingga siswa di seluruh dunia dapat langsung belajar berbicara dalam bahasa inggris dengan native speaker. Kelas ini tersedia setiap 15 menit sekali bagi siswa di pusat pelatihan tersebut. Setelah mengajar, pengajar akan memberikan penilaian kepada siswanya melalui aplikasi yang disediakan oleh perusahaannya tersebut seperti pada Gambar 9.

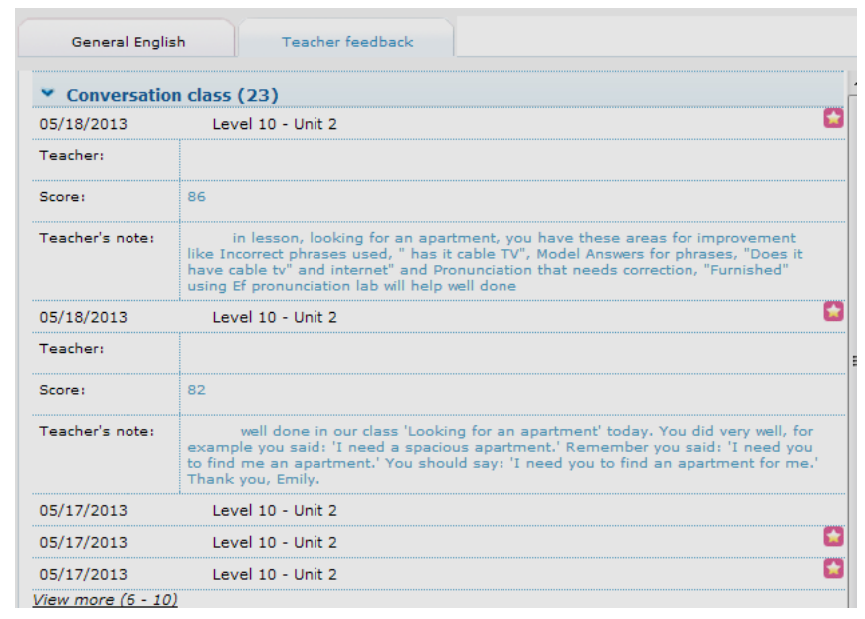

Gambar 9 Penilaian conversation class. (EF English First)

Kemudian secara bergantian, pengajar, akan diminta untuk memperbarui bahan dan materi pengajaran untuk kelas reading, grammar dan vocabulary (Gambar 10). Selain itu, pengajar juga akan melakukan evaluasi terhadap siswa di kelas writing, yang biasanya ia lakukan pada sore hari.

Siswa dapat melihat hasil evaluasi pada inbox nya masing-masing setelah $\log$ in ke website kelas online-nya.

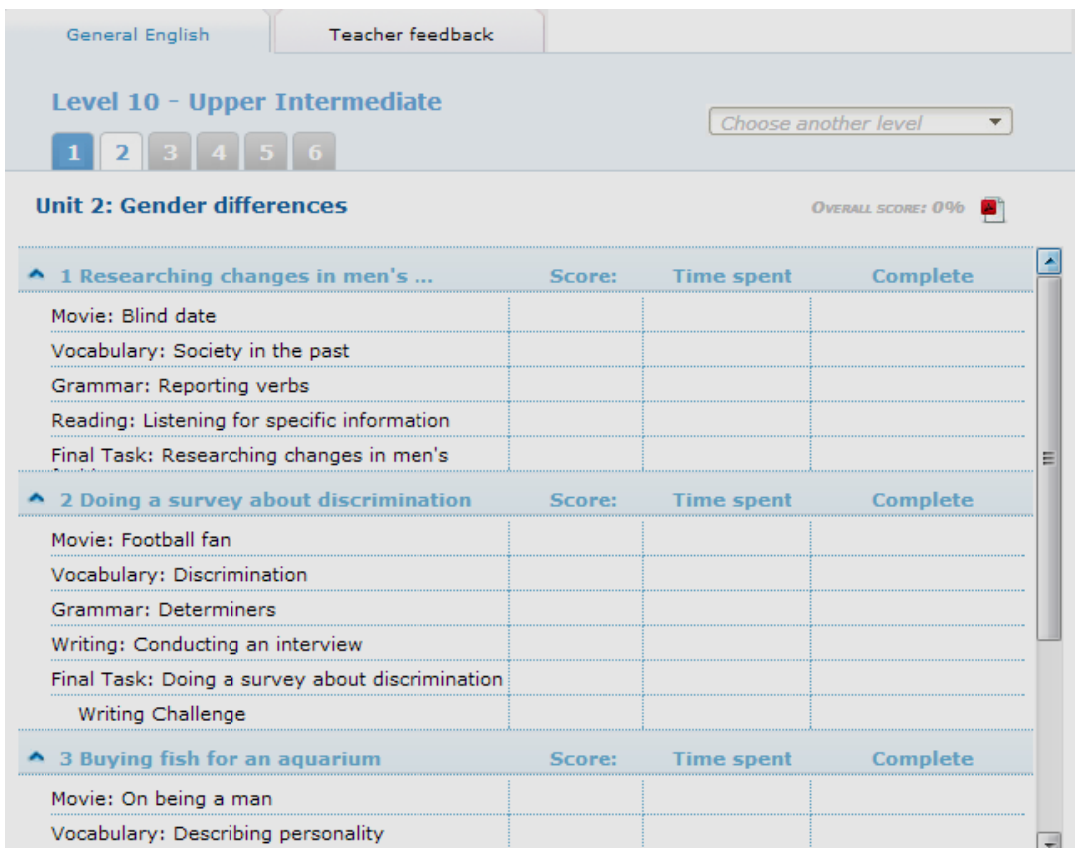

Gambar 10 Materi online class 


\section{The Benefit and Challenge}

Selain meningkatkan kepuasan karyawan sehingga bisa meningkatkan daya tarik dan daya ingat staf juga dari sisi operasional, karena mereka dapat meluangkan waktu lebih banyak bersama keluarganya, benefit dari home working ini adalah meningkatkan penghematan biaya dari penerapan hot desking, terutama yang berasal dari biaya rental kantor yang biasanya dihitung per meter persegi, keperluan seperti listrik, dan biaya dari staff turnover. Selain itu, dapat menjaga kerahasiaan data perusahaan, karena dengan begitu, pegawai dapat menjalankan inisiatif clean desk policy.

Namun demikian ada beberapa tantangan yang masih perlu untuk meningkatkan kesuksesan dari implementasi home working, misalnya seperti komitmen dari perusahaan untuk mau menjalankannya. Keraguan perusahaan untuk mengimplementasikan home working atau teleworking, terutama adalah karena jarak dianggap dapat menghambat proses interaksi, juga lingkungan rumah yang memungkinkan karyawan mudah terganggu (misalnya gangguan infrastruktur seperti listrik atau internet, gangguan dari anggota keluarga lainnya atau harus menerima tetangga yang berkunjung dan sebagainya) sehingga dapat mengurangi produktifitas seorang pekerja teleworking. Rainer (2012) di dalam artikelnya yang berjudul The Strengths and Weaknesses of Working from Home, mengemukakan bahwa untuk mengatasi permasalan di atas, banyak perusahaan akan banyak yang mengadopsi sistem hybdrid, di mana seorang pekerja masih diharuskan datang ke kantor selama 1 atau 2 hari selama seminggu.

Selain itu, Gibson, et al. (2002), di dalam tulisannya yang berjudul Telecommuting in the 21st century: Benefits, issues, and a leadership model which will work menyarankan bahwa untuk mengelola teleworkers yang semakin banyak diadopsi di abad 21 ini, seorang pemimpin dapat megadopsi gaya manajemen Situational Leadership ${ }^{\mathrm{TM}}$ (Gambar 11). Situational leadership mengajarkan seorang manager harus mampu untuk mengubah gaya kepemimpinan mereka tergantung dari sikap pegawainya, dan dari pekerjaan yang diberikan kepadanya.

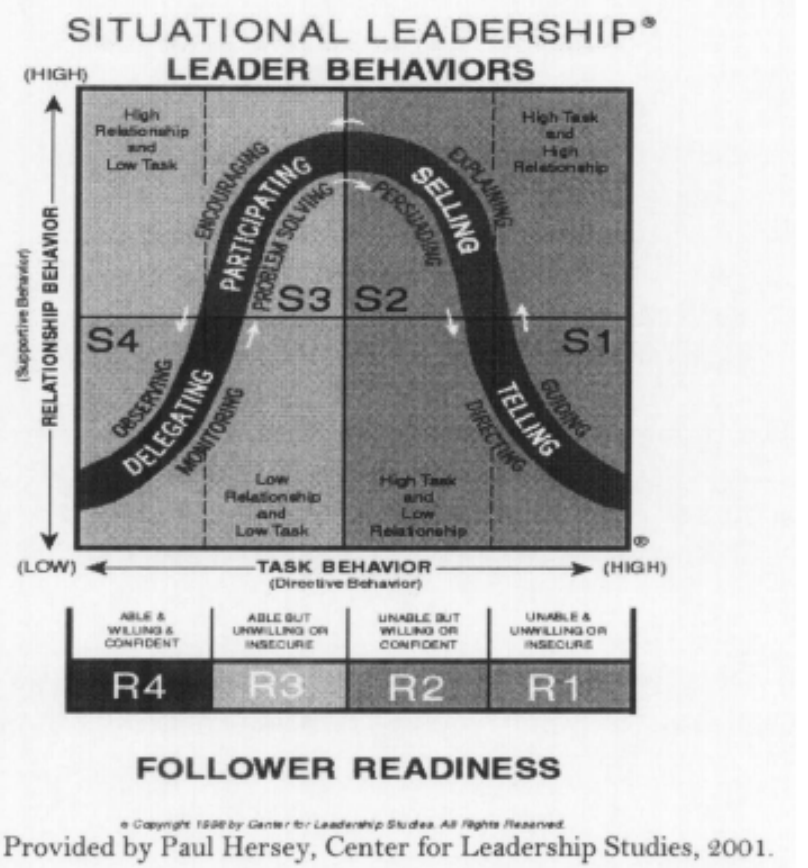

Gambar 11 Situational leadership (Hersey, 2001) 
S1 atau kepemimpinan jenis 1 terbentuk dari jumlah pekerjaan yang di atas rata-rata, dan hubungan di bawah rata - rata

S2 atau kepemimpinan jenis 2 terbentuk dari jumlah pekerjaan dan hubungan yang di atas rata - rata

S3 atau kepemimpinan jenis 3 terbentuk dari jumlah pekerjaan yang di bawah rata - rata, dan hubungan di atas rata - rata

S4 atau kepemimpinan jenis 4 terbentuk dari jumlah pekerjaan dan hubungan yang di bawah rata - rata

Dari gambar di atas, jika seorang pegawai home worker kurang bisa mengerjakan tugasnya dengan baik, dan merasa tidak aman atau dalam situasi ini adalah R1, seorang manager perlu untuk memberi bimbingan untuk mengarahkan karyawan ini, seperti S1. Namun jika berhadapan dengan pegawai yang sudah berpengalaman (expert) dan dewasa dengan karakteristik R3 atau bahkan R4, seorang manager lebih diharapkan dapat memonitor dengan cara mendengar (S4), memotivasi (S3), daripada memberitahu secara detail pekerjaan apa yang harus dikerjakan pegawai ini (S1).

Sementara itu Per (2011) dari IDA (Infocomm Development Authority of Singapore) mengemukakan bahwa ada beberapa faktor yang perlu diperhatikan dalam mengimplementasikan home working sehingga implementasinya dapat memberikan manfaat yang lebih yaitu: (1) pensejajaran dan persetujuan dari manajemen, sehingga ada dukungan dan komitmen baik berupa kebijakan maupun investasi yang dibutuhkan teleworking; (2) kesesuaian pekerjaan, karena tidak semua pekerjaan dapat dilakukan dari rumah, sehingga perusahaan harus mampu melihat pekerjaan apa saya yang akan lebih produktif jika dilakukan secara jarak jauh; (3) kebijakan organisasi dan alur kerja, untuk mengatur dan mengelola home worker karena memiliki proses dan karakteristik yang berbeda misalnya seperti mengubah pekerjaan menjadi tugas yang lebih kecil, mendistribusikan tugas ke workforce atau pegawai, Peer review untuk memastikan kualitas dari pekerjaan juga Reassemble completed tasks; (4) pemberdayaan melalui infrastruktur dan layanan ICT. Dari beberapa studi teleworking seperti di atas, teknologi yang pada umumnya digunakan untuk meng-enabled home working ini adalah sebagai berikut: communication and Collaboration seperti Video-conferencing, instant messaging, VOIP; information security, misalnya secure online data storage, desktop-as-a-service, managed firewall, etc; office productivity tools, misalnya office productivity suite, email dan sebagainya; digitised workflow, seperti project management software, Interactive Class application, Ticket service management, CRM, HRM, Enterprise workflow tools.

\section{The Opportunity}

Di Jakarta, Indonesia, pada 100 hari masa kerjanya, Joko Widodo dan Basuki Tjahaja Purnama, pasangan gubernur dan wakil gubernur, pernah mengemukakan bahwa salah satu visi dari jakarta adalah menjadi kota pintar. Kemudian Basuki pada suatu acara Jakarta Fashion Food Festival (2013) kembali menegaskan rencananya menjadikan Jakarta sebagai kota pintar (Akuntono, 2012). "Jakarta akan full dengan WiFi”, Basuki mengatakan Jakarta kota cerdas dimaksudkan supaya warga bisa bekerja di rumah tanpa menghabiskan banyak waktu di jalan. Hal ini akan berpengaruh pada kemacetan Jakarta. Orang akan lebih sedikit yang datang dan pergi ke suatu tempat. Demikian juga pada Technology Conference and Expo 2013, Basuki kembali mengemukakan harapannya agar penggerak perusahaan teknologi dapat mendukung visi misi Gubernur DKI Jakarta Joko Widodo dan Basuki untuk mewujudkan Jakarta sebagai sebuah kota pintar (Aziza, 2013).

Home working atau teleworking selain dapat mengurangi kemacetan di Jakarta, yang juga dapat berkontribusi dalam mengurangi penggunaan BBM, juga dapat meningkatkan pendapatan dari kontribusi inactive residence. Dengan jumlah penduduk tidak aktif (kerja) yang mengurus rumah tangga sebesar 33.6 juta orang (BPS, 2012), dan jumlah persentase penduduk indonesia yang kuliah sebesar 7.2\% (Pikiran Rakyat , 2012), juga 24.2\% penduduk indonesia mengakses internet (Santoso, 2012), mungkin bisa diasumsikan ada sebesar 580 ribu knowledge worker di indonesia yang sebelumnya pernah bekerja tetapi saat ini memilih untuk mengurus keluarga. 
Sehingga mungkin pemerintah indonesia, khususnya pemerintah jakarta, dapat juga memulai dengan cara membentuk suatu pilot project bersama dengan vendor telekomunikasi, ISP, perusahaan dan universitas seperti yang dilakukan IDA di singapura.

\section{SIMPULAN}

Perkembangan teknologi informasi dan telekomunikasi pada saat ini sangat memungkinkan orang untuk bekerja dari rumah, yang dapat memberikan banyak manfaat seperti memberikan waktu yang lebih fleksibel bagi seorang karyawan untuk melakukan kegiatan bersama keluarga, seperti yang dilakukan oleh karyawan di PT "ABC" yang sudah menerapkan konsep home working sepenuhnya, atau di PT "XYZ” yang menerapkan konsep hybrid, yaitu seorang karyawan diperkenankan untuk bekerja selama satu hari di rumah dan empat hari di kantor per minggu. Berdasarkan hasil survei karyawan tahunan yang diadakan oleh departemen sumber daya manusia, kepuasan karyawan di PT "XYZ" meningkat setelah perusahaan menerapkan kebijakan home working ini karena telah membantu meningkatkan work-life balance seorang pegawai. Namun demikian, pengaruh penerapan home working terhadap kepuasan karyawan memerlukan penelitian lebih lanjut dengan populasi yang lebih besar. Manfaat kedua dari home working berdasarkan observasi peneliti adalah bahwa perusahaan dapat menerapkan kebijakan hot desking dimana hal ini dapat meningkatkan penghematan biaya di perusahaan dengan cara melakukan penghematan terhadap ruang kerja. Hal ini memungkinkan karena 20\% karyawan setiap harinya akan bekerja dirumah, sehingga perusahaan cukup menyediakan ruang kerja untuk 80 - 90\% jumlah karyawan saja. Selain itu, implementasi hot desking dapat mendukung insiatif clean desk policy, yang bertujuan untuk menjaga kerahasiaan data perusahaan, yang bertujuan untuk meningkatkan keamanan kantor dari kebocoran informasi, juga kebersihan di dalam kantor. Penelitian lebih lanjut diperlukan untuk dapat menganalisa apakah perusahaan di Indonesia dapat menerapkan inisiatif ini, karena penerapan home working di Indonesia, khususnya jakarta, akan membutuhkan kerja sama antara perusahaan penyedia infrastruktur, perusahaan tempat para pekerja dan karyawan itu bekerja, juga pemerintah didalam mendorong, mendukung dan memfasilitasi inisiatif home working ini agar dapat terwujud sehingga dapat meningkatkan kontribusi dari inactive residents, dan bahkan dipercaya dapat juga mengurangi masalah sosial di kota besar seperti kemacetan di Jakarta.

\section{DAFTAR PUSTAKA}

Akuntono, I (2012). Jokowi-Basuki Ingin Jadikan Jakarta sebagai "Kota pintar". Diakses dari http://megapolitan.kompas.com/read/2012/10/29/18450757/Jokowi-Basuki.Ingin.Jadikan.Jaka rta.sebagai.Smart.City.

Alexander, B., Dijst, M., dan Ettema, D. (2010). Working from 9 to 6? An analysis of in-home and out-of-home working schedules. Transportation, 37, 505-523.

Aziza , K. S. (2013). Basuki Minta Penggerak Teknologi Dukung "Kota Pintar". Diakses dari website Kompas:

http://lipsus.kompas.com/gebrakan-jokowi-basuki/read/xml/2013/05/14/12243832/Basuki.Min ta.Penggerak.Teknologi.Dukung.Smart.City.

BPS. (2012). Survei Angkatan Kerja Nasional (SAKERNAS) 2004, 2005, 2006, 2007, 2008, 2009, 2010, 2011 dan 2012. Diakses dari website BPS: http://www.bps.go.id/tab_sub/view.php?kat=1\&tabel=1\&daftar=1\&id_subyek=06\&notab=4. 
CISCO. (2007). Cisco Ip Communicator V2.0. Diakses dari http://ebookee.org/Cisco-Ip-Communicator-V2-0_32743.html.

CISCO. (2012). IPSec VPN QoS Design. Diakses dari http://www.cisco.com/en/US/docs/solutions/Enterprise/WAN_and_MAN/QoS_SRND/IPSecQ oS.html.

Crosbie, Tracey and Moore, Jeanne. (2004). Work-life balance and working from home. Social Policy \& Society, 3(3), 223-233. Psychology Section, School of Social Sciences, University of Teesside, Middlesbrough, UK.

Dr. Phil. (2012). Stay-at-Home Moms vs. Working Moms. Diakses dari website Dr.Phil: http://drphil.com/articles/article/284.

EF English First. (2013). English Town. Diakses dari http://www.englishtown.com/school/course/.

Gibson, Jane W., Blackwell, Charles W., Dominicis, P., Demerath, N. (2002). Telecommuting in the 21st century: Benefits, issues, and a leadership model which will work. Journal of Leadership \& Organizational Studies, 8 (4), 75 - 86.

Hersey, Paul. (2001). Situational Leadership. Center for Leadership Studies.

Jalote, Sumedha. (2013). ICT enabled work-from-home pilot launched in Singapore. Citizen Engagement, Digital Inclusion. Diakses dari http://www.futuregov.asia/articles/2013/mar/14/ict-enabled-work-home-pilot-launched-singap ore/

Kaplan, R.S. (2010 ). Conceptual foundations of the balanced scorecard. Working Paper Harvard Business School, Harvard University. Diakses dari http://www.hbs.edu/faculty/Publication\%20Files/10-074.pdf.

Per L. S. (2011). Introduction to ICT enabled Home based Work. Diakses dari http://www.ida.gov.sg/ /media/Files/Infocomm\%20Landscape/Infrastructure/Wired/IntroToH BW_IDA.pdf.

Photo Bucket. (2013). Virtual Classroom Screenshots. Diakses dari http://s587.photobucket.com/user/cmeonline/media/virtual\%20classroom\%20screenshots/web ex.gif.html.

Pikiran Rakyat. (2012). Baru 7,2 Persen Anak Bangsa Nikmati Bangku Kuliah. Diakses dari http://www.pikiran-rakyat.com/node/188222.

Private Sense. (2011). Clear Desk Policy. Diakses dari http://www.privacysense.net/clear-desk-policy/.

Santoso, I (2012). Pengguna Internet Indonesia 2012 Capai 63 Juta Orang. Diakses dari website Antara: http://www.antaranews.com/berita/348186/pengguna-internet-indonesia-2012-capai-63-juta-or ang 